
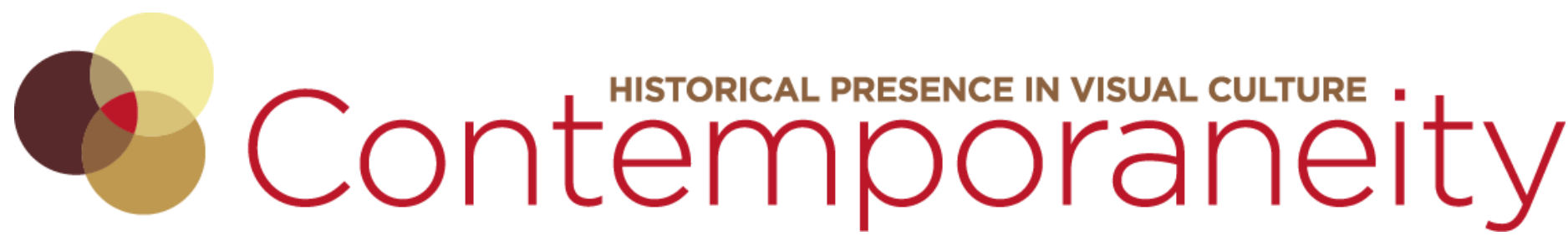

Vol 6, No 1 "Boundless" (2017) | ISSN 2153-5914 (online) | DOI 10.5195/contemp.2017.215

http://contemporaneity.pitt.edu

\title{
SYNAXIS
}

Julia Lambright

\section{About the Artist}

Julia Lambright was born and raised in Russia. She received an MFA with distinction in painting from the University of New Mexico in 2015. Having worked primarily in oil in the past, her focus over the last decade has been rooted in traditional egg-tempera painting, a technique that she learned from masters in Russia and the United States. While searching for a personal spiritual experience, Lambright began exploring iconographic canons, formulas, and techniques of seventeenth-century icon painting. Being influenced by the icon's visual aesthetics, with the images rooted in symbols and signs, Lambright integrates and transforms its principles and technical construction into a contemporary form of art making. Her work can be found at http://www.julialambright.com/

Currently, Lambright is a visiting lecturer at the University of New Mexico, Valencia Campus, Department of Business, Technology, and Fine Arts. 


\section{SYNAXIS}

\author{
Julia Lambright
}

Having emigrated from Russia to the United States in 2003, I recognized new possibilities for myself while strengthening my connection to American culture. My exposure to the American way of life allowed me to re-envision the cultural, social, and political climate of present-day Russia, as well as to reflect, learn, and analyze the interplay of ethnic and geographical influences. In many ways, American culture has shaped my ideas for developing the concept of the "Other." For me, "othering" became a mental classification for losing some of my spiritual and physical connection with Russian society. Yet, in the United States, I am also regarded as "the Other." And so, what should "home" signify to and for me?

For me, "home" is now a dialogue and negotiated space; it is a process by which I am constantly constructing, defining, and redefining my own cultural identity. Searching for communion and internal revelation, I felt a growing need to explore the sacred art of Russian icons. Being compared to the "gate" between a believer and God, icons represent a dogmatic truth that aims to intimately connect with the viewer. Engaging with this world of sign and symbols, "Synaxis" stands as a metaphor for a borderline (both physical and spiritual) that simultaneously separates and connects all of us in this global community. Observing the complexity of cultural codes, I want to awaken a range of human emotions, encourage a visual recognition and a dialogue of looking, seeing, and realizing that there is no "Other."

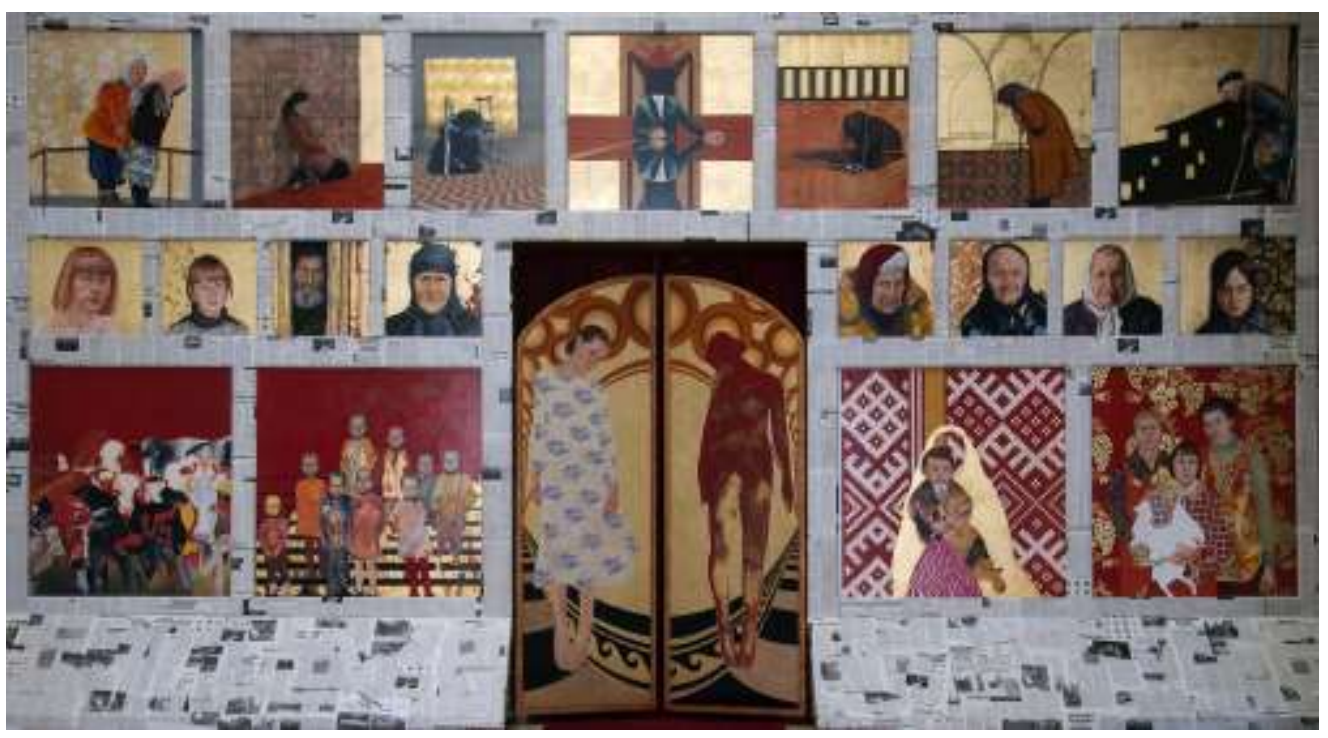

Figure 1

Installation view of Synaxis, South Broadway Cultural Center, Albuquerque, photograph by Julia Lambright, 2015. 


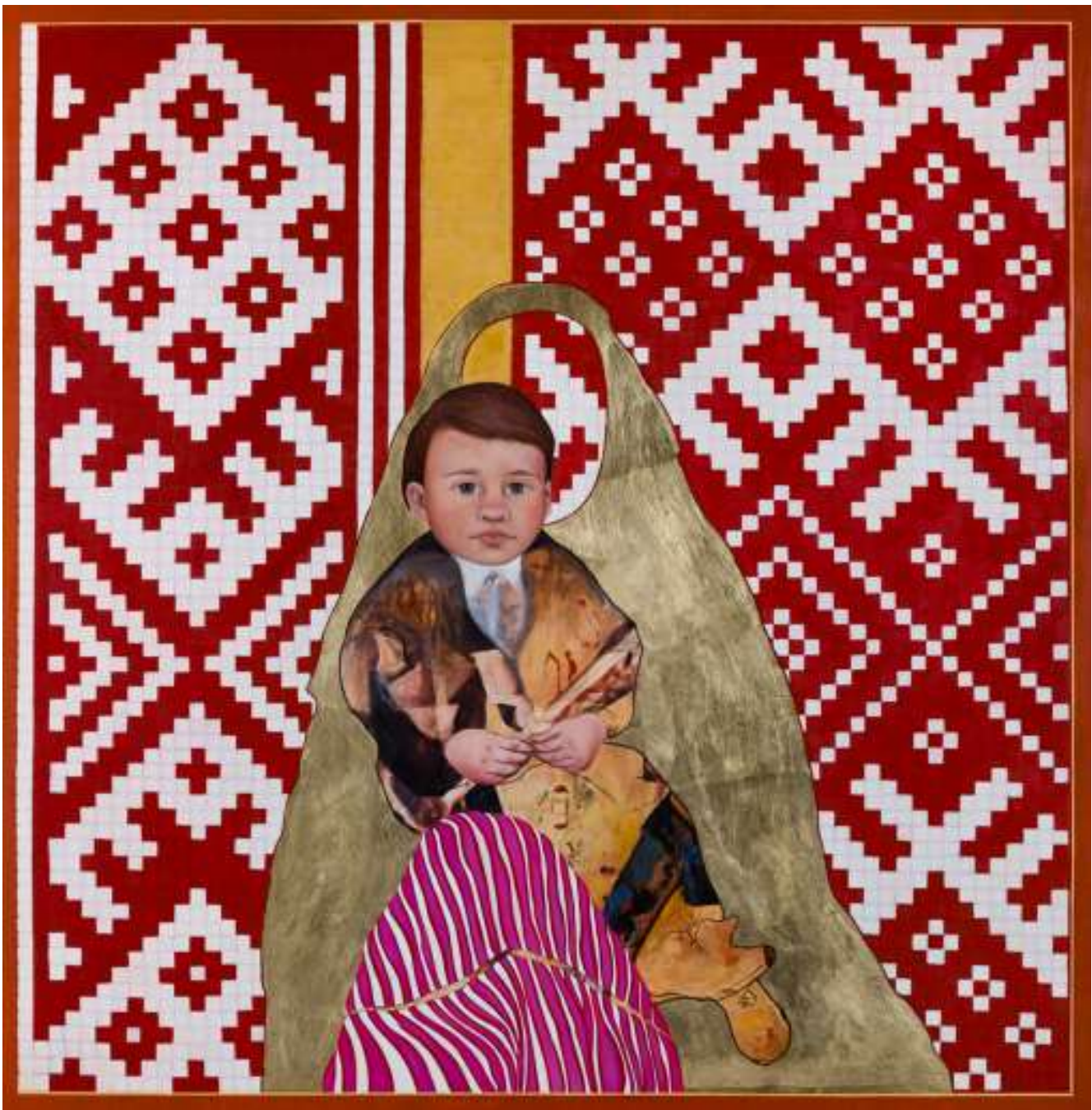

Figure 2

Julia Lambright, Tetris, 2013, egg tempera, oil, and gold leaf on panel, $36.5 \times 36 \times 0.5 \mathrm{in}$. 


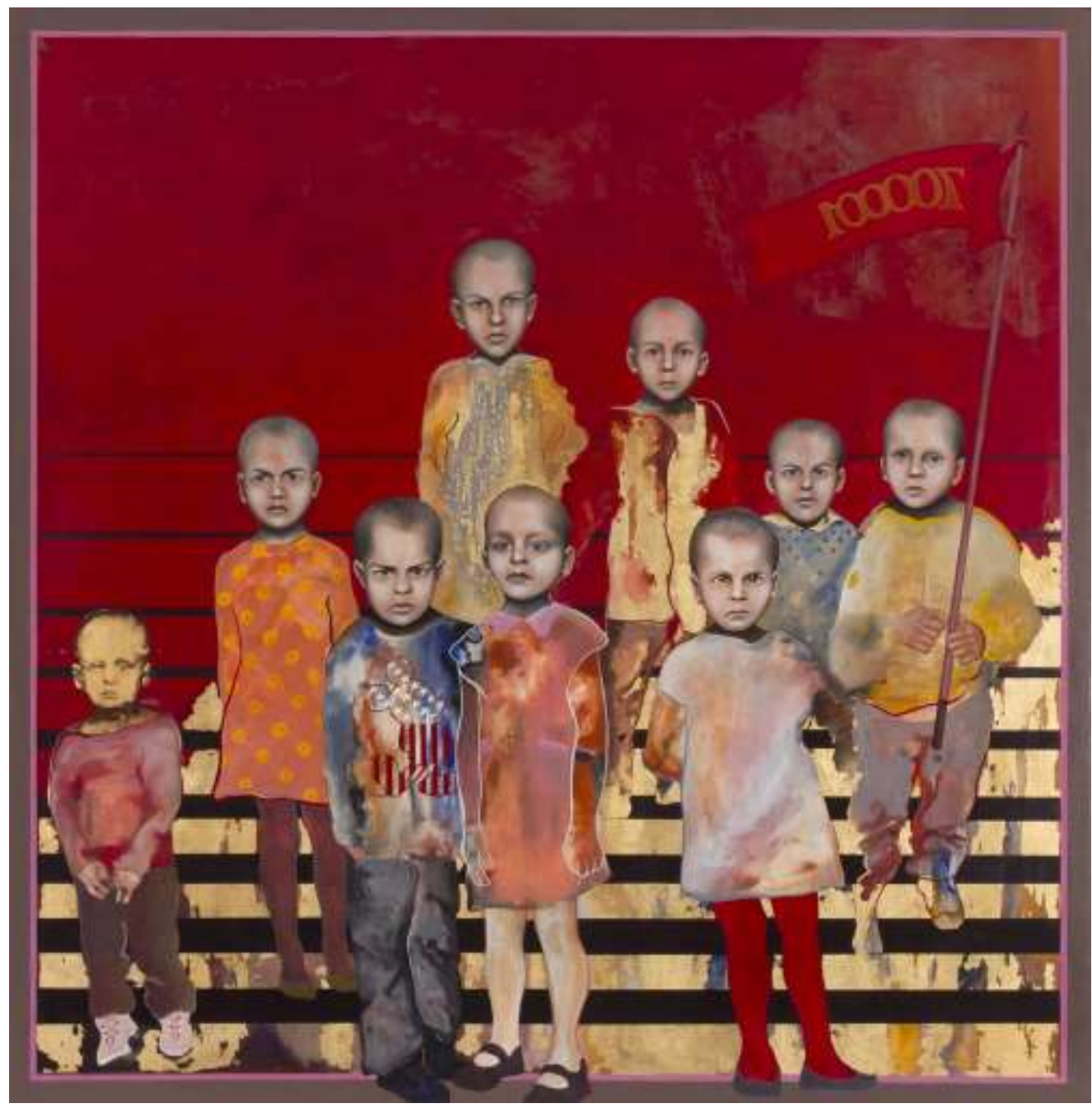

Figure 3

Julia Lambright, 700,000 in One, 2014, egg tempera and gold leaf on panel, $36.5 \times 36 \times 0.5$ in. 


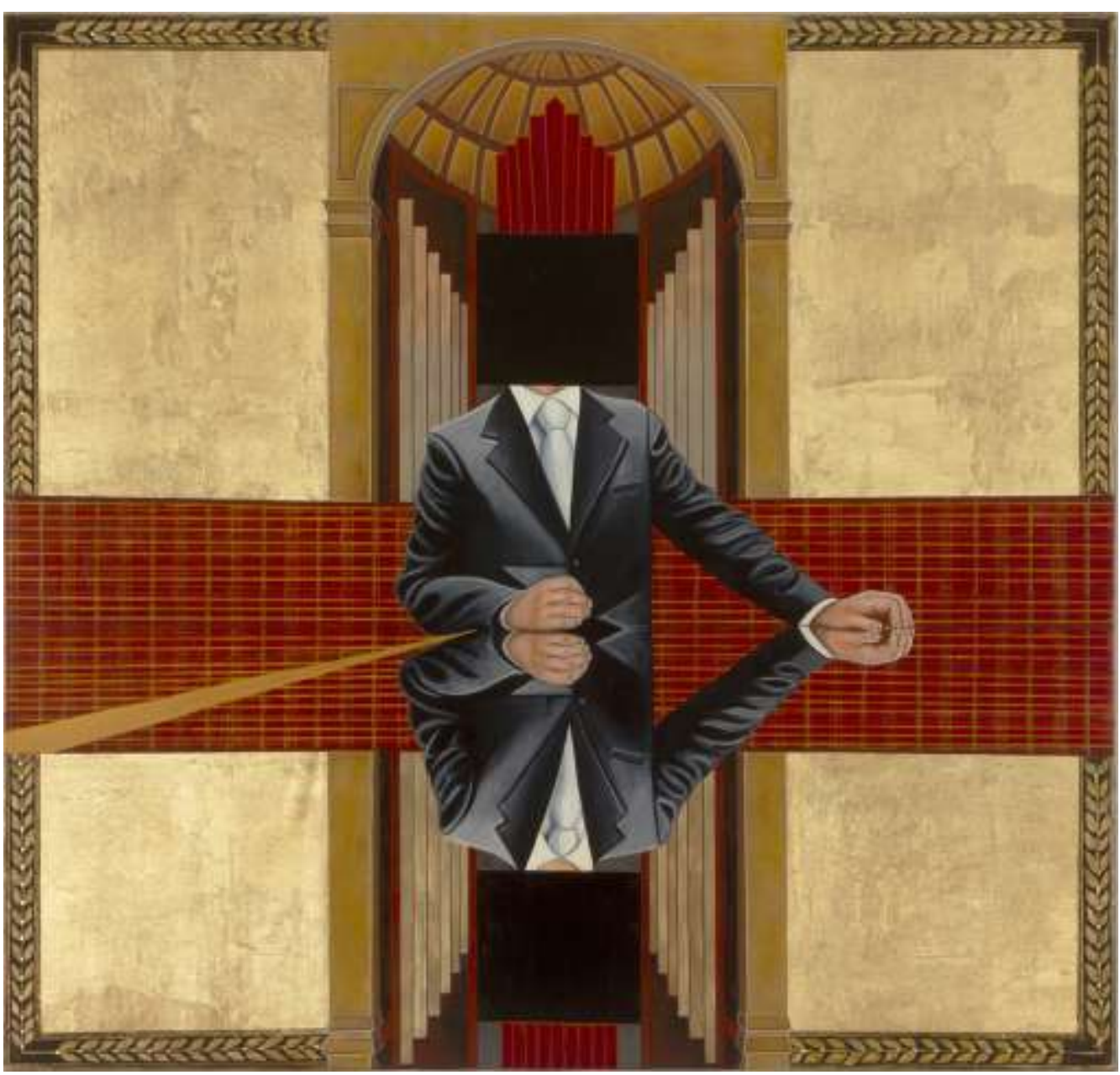

Figure 4

Julia Lambright, Desert Crossing, 2015, egg tempera and gold leaf on panel, $28.5 \times 30 \times 0.5$ in.

$(\mathrm{cc}) \mathbf{E Y}$

New articles in this journal are licensed under a Creative Commons Attribution 4.0 United States License.

\section{ULIS D-Sunk}

This journal is operated by the University Library System of the University of Pittsburgh as part of its D-Scribe Digital Publishing Program, and is co-sponsored by the University of Pittsburgh Press. 